\title{
Axonal extension from dorsal root ganglia on fibrillar and highly aligned poly(lactic acid)-polypyrrole substrates obtained by two different techniques: electrospun nanofibres and extruded microfibres
}

\author{
Fernando Gisbert Roca ${ }^{a}$, Jorge Más Estellés ${ }^{a, b}$, Manuel Monleón Pradas ${ }^{a, b}$ and Cristina Martínez-Ramos ${ }^{a, c, *}$ \\ The biological behaviour of Schwann cells (SCs) and dorsal root ganglia (DRG) on fibrillar, highly aligned and electroconductive substrates obtained by two \\ different techniques is studied. Mats formed by nanometer-sized fibres of poly(lactic acid) (PLA) are obtained by the electrospinning technique, while \\ bundles formed by micrometer-sized extruded PLA fibres are obtained by grouping microfibres together. Both types of substrates are coated with the \\ electrically conductive polymer polypyrrole (PPy) and their morphological, physical and electrical characterization is carried out. SCs on micrometer-sized \\ substrates show a higher motility and cell-cell interaction, while a higher cell-material interaction with a lower cell motility is observed for nanometer-sized \\ substrates. This higher motility and cell-cell interaction of SCS on the micrometer-sized substrates entails a higher axonal growth from DRG, since the \\ migration of SCs from the DRG body is accelerated and, therefore, the SCs tapestry needed for the axonal growth is formed earlier on the substrate. A higher \\ length and area of the axons is observed for these micrometer-sized substrates, as well as a higher level of axonal sprouting when compared with the \\ nanometer-sized ones. These substrates offer the possibility of being electrically stimulated in different tissue engineering applications of the nervous \\ system.
}

Keywords: Poly(lactic acid), Polypyrrole, Aligned substrates, Biological behaviour, Schwann cells, Dorsal root ganglia

\section{Introduction}

The treatment of injuries both at the central nervous system (CNS) and at the peripheral nervous system (PNS) presents great difficulties since the loss of cells, the creation of neurotoxic environments with axonal growth inhibiting factors and the effect of other partially unknown factors make it very difficult to achieve a functional axonal regeneration, especially at the CNS and at long PNS injuries $[1,2]$. Therefore, the current approach for the treatment of nerve injuries is based on multi-combinatorial techniques based on the transplantation of cells seeded on biomaterials capable of both guiding axonal growth and protecting transplanted cells [3,4]. In addition, the application of various types of stimuli (mechanical, electrical and biochemical) has also been widely studied with the aim of improving axonal growth [5-8]. Within this approach, electrically conductive substrates have been used to improve the axonal extension of neurons and induce a greater release of neurotrophins by glial cells when subjected to an exogenous electric field [9,10].

The interaction between cells and biomaterials is mainly based on topographic interactions through adhesion and mechanotransduction signals [11,12]. Therefore, it is of great importance to study the topography of the substrates in order to direct axonal growth towards a target through the mechanical constriction of cells $[13,14]$. Many studies have concluded that a substrate based on aligned fibres is capable of guiding axonal growth, whereas in a flat substrate such as a glass cover or a substrate with randomly oriented fibres, axons grow unoriented [13-18]. Besides the relevance of having an aligned substrate, the size of the fibres that form the substrate is also critical. Different studies have concluded that the diameter of the fibres that form the substrate is able to influence the biological behaviour in terms of neurite outgrowth, Schwann cell migration and differentiation and proliferation of neural stem cells [1921]. However, these studies have focused solely on electrospun nanometer-sized fibres, with a maximum diameter of the nanofibres of around $1,000 \mathrm{~nm}$.

Two basic techniques can be used to manufacture poly(lactic acid) aligned fibre substrates, either producing the fibres from a solution by electrospinning, or to employ fibres obtained by mechanical extrusion. The electrospinning technique is based on the electrostatic production of nanofibres by applying electrical forces to a polymer solution and yields nanofibres with diameters between ten and one thousand nanometers [22,23]. On another hand, fibres obtained by the extrusion technique are larger, typically with diameters in the range between the tens and the hundreds of micrometers [24].

A key role in axonal regeneration is played by glial nerve cells since they supply growth factors and biochemical signals that are necessary for axonal growth [25-30]. Among them the Schwann cells (SCS) stand out because they are essential for neuronal survival

\footnotetext{
${ }^{a}$ Center for Biomaterials and Tissue Engineering, Universitat Politècnica de València, Cno. de Vera s/n, 46022, Valencia, Spain

${ }^{\mathrm{b}}$ CIBER-BBN, Biomedical Research Networking Center in Bioengineering Biomaterials and Nanomedicine, Spain

'Universitat Jaume I, Unitat predepartamental de Medicina, Avda/Sos Baynat, S/N, 12071 Castellón de la Plana, Spain

*Corresponding author: Cristina Martínez Ramos. Centro de Biomateriales e Ingeniería Tisular, Universidad Politécnica de Valencia, Camino de Vera s/n E-46022 Valencia, España. Tel.: +34963877000. E-mail: crimarr2@upvnet.upv.es
} 
and axonal regeneration in the peripheral nervous system [31-33]. SCs are responsible of maintaining the myelin sheath around the axons and secrete different neurotrophic factors like the nerve growth factor (NGF), the brain-derived neurotrophic factor (BDNF) and the neurotrophin-3 (NT-3), among others [31-33]. These neurotrophic factors are essential to create a biochemical environment that favours axonal growth. Furthermore, in the case of injury SCs promote axonal regeneration by forming cell columns (called Büngner bands) that guide the regenerating axons [34,35]. SCs also release cytokines as LIF and IL-6 that promote the survival of neurons [31].

Axon regeneration can also be enhanced through mechanical and electrical stimuli, which has directed attention to electroconductive biomaterials such as electroconductive polymers. Among them, polypyrrole (PPy), polyaniline (PANI) and poly(3,4-ethylenedioxythiophene) (PEDOT) have been well studied. PPy has been widely used in biomedical applications, especially in nerve tissue engineering scaffolds, due to its high electrical conductivity, long-term ambient stability, good biocompatibility, low cost and facile synthesis by chemical or electrochemical polymerization [15,36-43]. It must be considered that PPy is an intractable solid with poor mechanical processability, which limits its direct application to obtain substrates with a specific topography [36]. For that reason, the strategy of coating the surface of other insulating polymers with PPy is interesting in order to exploit both the intrinsic electrical conductivity of PPy and the better mechanical properties of the insulating host polymer $[15,36,44]$. We chose poly-L-lactic acid (PLA) as host polymer of the substrates because it is a low cost, renewable, environmentally friendly and biodegradable biomaterial $[45,46]$. The biocompatibility of both PLA and PPy makes it possible to use PLA-PPy substrates in tissue engineering and biomedical applications $[47,48]$. In addition, despite PPy is a nonbiodegradable polymer, it has been observed that the PPy coating of PLA substrates do not prevent the biodegradation of PLA and it only could retard slightly its degradation, while the PPy content is low [49-51].

In this study, we compare axonal growth on flat, fibrillar and unidirectional substrates obtained by two different techniques: electrospinning and mechanical extrusion. Thus, fibre sizes of two different orders of magnitude are obtained: nanofibres and microfibres. On the one hand, aligned nanofibre mats were prepared using the electrospinning technique in order to obtain nanometer-sized fibres (approx. $500 \mathrm{~nm}$ diameter). On the other hand, $10 \mu \mathrm{m}$ diameter microfibres were grouped in parallel with polycaprolactone (PCL) fasteners placed in their ends to obtain flat rail shaped microfibre bundles. PCL was used as fastening material for the microfibres bundles due to its low melting point (around $60^{\circ} \mathrm{C}$ ), which facilitated the manufacture of the microfibre bundles. $\mathrm{PCL}$ is a biodegradable and biocompatible polymer widely used in biomedical applications as an implantable biomaterial $[52,53]$. Both kinds of substrates were then coated with the electroconductive polymer PPy.

To study the axonal extension on our substrates, we chose dorsal root ganglia (DRG) as neuron source since the DRG body can be taken as a starting point for the axon's growth from the neuron somas that remain inside the DRG during axon extension. Furthermore, the cells that migrate from the DRG body (mostly SCs) generate a cellular environment that favours axonal extension $[19,21]$. Thus, flat and highly aligned PPy-coated PLA substrates were manufactured based on fibrils with diameters of two different orders of magnitude (nanofibres and microfibres), with the goal of studying the influence of this parameter on axonal extension. This study may be of interest to optimize fibre diameter in electroconductive substrates that could find use as part of an electrical stimulation bioreactor and in applications in neural tissue engineering.

\section{Experimental section}

\subsection{Preparation of nanofibre mats and microfibre bundles}

Aligned PLA nanofibre (NF) mats (approximately $500 \mathrm{~nm}$ diameter) were obtained by the electrospinning technique. First, PLA (INGEO 40420 RESINEX) (10\% wt\%) was dissolved in dichloromethane (DCM)/dimethylformamide (DMF) (70/30 v/v) and stirred for 12 hours at room temperature. Then, the solution was introduced into a $12 \mathrm{~mL}$ syringe with an internal diameter of $15.77 \mathrm{~mm}$ attached to a precision stainless steel needle with $0.15 \mathrm{~mm}$ of internal diameter (30G). Aligned nanofibres were obtained by applying a voltage of $20 \mathrm{kV}$ between the needle tip and the collector, maintaining the flow rate at $3 \mathrm{~mL} / \mathrm{h}$ and collecting the nanofibres during 1.5 hours on a round plate wrapped with an aluminium foil with a diameter of $15.5 \mathrm{~cm}$ which centre was located $20 \mathrm{~cm}$ from the needle tip and that was rotating at 32 rps. These parameters were chosen from preliminary experiments carried out to establish the optimal conditions (homogeneous fibres, absence of precipitates, etc).

After electrospinning, PLA membranes were air-dried for 2 days and introduced in a desiccator with a fixed vacuum at room temperature for another 2 days. Finally, PLA membranes were introduced between two glass plates subjected to compression and they underwent a tempering process consisting of stove heating at $90^{\circ} \mathrm{C}$ with $100 \%$ of ventilation for $15 \mathrm{~min}$ and subsequent cooling at $-20^{\circ} \mathrm{C}$ for 2 hours. With this tempering process, a stiffening of the PLA membranes was achieved, which prevented them from wrinkling when they were introduced into water.

Aligned PLA microfibre (MF) bundles were obtained by grouping 1,200 PLA microfibres with a diameter of $10 \mu \mathrm{m}$ (Aitex, Spain). In order to maintain the alignment of the lane-shaped microfibre bundles, they were fastened using PCL bands, which were placed in a solid state on both extremes of the lane and melted by temperature so that, once cooled, the microfibres were attached by the PCL bands.

NF and MF substrates with dimensions of $20 \mathrm{~mm} \times 4 \mathrm{~mm}$ (length $\mathrm{x}$ width) were used. It should be noted that the auxiliary PCL bands that hold the MFs together are not considered when defining the dimensions of the MF substrates. 


\subsection{Polypyrrole coating}

Both substrates were coated with the electrically conductive polymer PPy via in situ polymerization. As a previous step, the substrates were immersed in deionized water under compression and a fixed vacuum was applied until they stopped floating and, therefore, the introduction of water inside the spaces between fibres was achieved, in order to obtain a homogeneous coating of all nano and micro fibres, not only the most superficial ones. Next, each substrate was put into a polypropylene tube with an aqueous solution of pyrrole monomer (Py, Sigma-Aldrich 131709) and sodium para-toluene sulfonate (pTS, Sigma-Aldrich, 152536), followed by ultrasonication for 1 min in order to allow the membrane to be saturated with Py/pTS solution. The substrates were incubated with shaking at $4^{\circ} \mathrm{C}$ for $1 \mathrm{~h}$. The ratio between the substrate area (length $\mathrm{x}$ width) and the final volume of the Py/pTS aqueous solution was $0.6 \mathrm{~cm} / \mathrm{mL}$ and the different concentrations of Py and pTS that were used are described in Table 1. Then, an aqueous solution of ferric chloride $\left(\mathrm{FeCl}_{3}\right.$, Sigma-Aldrich 157740) was added and incubated with shaking at $4^{\circ} \mathrm{C}$ for $24 \mathrm{~h}$ for the polymerization and deposition of PPy on the PLA substrates. The ratio between the substrate area (length $\mathrm{x}$ width) and the final volume of the $\mathrm{FeCl}_{3}$ aqueous solution was $0.6 \mathrm{~cm}^{2} / \mathrm{mL}$ and the different concentrations of $\mathrm{FeCl}_{3}$ that were used are described in Table 1. PPy-coated membranes were washed with deionized water with agitation for $10 \mathrm{~min}$ for three times and ultrasonicated for $30 \mathrm{~min}$ in deionized water for three times. Finally, the membranes were dried in a desiccator with a fixed vacuum at $40^{\circ} \mathrm{C}$ for 2 days.

\section{Table 1}

Reaction parameters used for the PPy coating of NF and MF substrates.

\begin{tabular}{cccccc}
\hline Coating protocol & {$[\mathrm{Py}](\mathrm{mM})$} & {$[\mathrm{pTS}](\mathrm{mM})$} & {$\left[\mathrm{FeCl}_{3}\right](\mathrm{mM})$} & $\begin{array}{c}\text { Reaction } \\
\text { time }(\mathrm{h})\end{array}$ \\
\hline $\mathrm{C} 1$ & 7 & 7 & 19 & 24 \\
$\mathrm{C} 2$ & 14 & 14 & 38 & 24 \\
\hline
\end{tabular}

\subsection{Mass fraction and effective coating thickness of PPy}

The mass fraction of PPy $\left(\omega_{P P y}\right)$ deposited on PLA substrates was measured by weighing them before $\left(m_{0}\right)$ and after $\left(m_{f}\right)$ the PPy coating using a precision balance (AX205, Mettler-Toledo Inc., sensibility of $0.01 \mathrm{mg}$ ) and applying Eq. (1) (n=3).

$\omega_{P P y}=\frac{m_{P P y}}{m}=\frac{m_{f}-m_{0}}{m_{f}}$

The effective coating thickness of PPy (e) was obtained by applying Eq. (2), approximating the section of the PPy coating on each fibre to a rectangle due to its low thickness. $V_{P P y}, m_{P P y}$ and $\rho_{P P y}$ are the volume, mass and density of PPy, respectively, and $r, L$ and $n$ are the radius, length and number of fibres, respectively.

$V_{P P y}=\frac{m_{P P y}}{\rho_{P P y}}=2 \cdot \pi \cdot r \cdot e \cdot L \cdot n$

The number of NFs $\left(n_{N F}\right)$, the ratio of the number of fibres $\left(n_{N F} / n_{M F}\right)$ and the surface area ratio between NF and MF substrates $\left(S_{N F} / S_{M F}\right)$ were obtained by applying Eq. (3), Eq. (4) and Eq. (5), respectively, where $V_{N F}$ is the volume of a NF substrate, $V_{1} N F$ is the volume of one NF, $m_{N F}$ is the mass of a NF substrate, $m_{M F}$ is the mass of a MF substrate and $\rho_{P L A}$ is the density of PLA.

$n_{N F}=\frac{V_{N F}}{V_{1 N F}}=\frac{\frac{m_{N F}}{\rho_{P L A}}}{\pi \cdot r_{N F}^{2} \cdot L}$

$\frac{n_{N F}}{n_{M F}}=\frac{\frac{n_{N F}}{m_{N F}}}{\frac{n_{M F}}{m_{M F}}}$

$\frac{S_{N F}}{S_{M F}}=\frac{2 \cdot \pi \cdot r_{N F} \cdot L \cdot \frac{n_{N F}}{m_{N F}}}{2 \cdot \pi \cdot r_{M F} \cdot L \cdot \frac{n_{M F}}{m_{M F}}}$ 


\subsection{Morphological characterization by field emission scanning electron microscopy (FESEM)}

For the characterization of the surface morphology of membranes, a field emission scanning electron microscope (FESEM; ULTRA 55, ZEISS Oxford Instruments) was used. The preparation of the samples consisted primarily in desiccation under vacuum conditions during the $24 \mathrm{~h}$ prior to the test to avoid interferences due to evaporated water. Subsequently, samples were placed on a carbon tape and a carbon bridge was created between the sample and the carbon tape. Finally, samples were coated with a thin layer of platinum. The voltage used was $2 \mathrm{kV}$.

\subsection{Electrical characterization}

The electrical behaviour was studied by measuring superficially the circulating electric current (DC) when applying a known voltage, that allowed us to calculate the apparent surface electrical resistance of the materials $(R)$ by Ohm's law. After measuring the distance between contacts (d) and the cross section of the substrates $(\mathrm{S})$, the in-plane apparent DC-conductivity $\left(\sigma_{D C}\right)$ of the materials was obtained by Eq. (6) ( $n=6)$. By applying Eq. (7) the conductivity of the PPy coating $\left(\sigma_{D C P P y}\right)$ was also obtained $(n=6)$.

$\sigma_{D C}=\frac{d}{R \cdot S}$

$\sigma_{D C P P y}=\frac{d}{R \cdot S_{P P y}}=\frac{d}{R \cdot 2 \cdot \pi \cdot r \cdot e \cdot n}$

\subsection{Substrates sanitization and preconditioning}

Before cell seeding, substrates were sanitized by $30 \mathrm{~min}$ exposure to UV irradiation (UV lamp, wavelength $254 \mathrm{~nm}$ ) on each side and immersion in 70\% ethanol (ET00021000, Scharlab) for 3 washes of $10 \mathrm{~min}$. Thereafter the ethanol residues were removed by performing 4 washes of $10 \mathrm{~min}$ with ultrapure water (Mili- $\left.{ }^{\circledR}\right)$. The preconditioning of the materials was done by immersion in Dulbecco's Modified Eagle Medium with a high glucose level $(4.5 \mathrm{~g} / \mathrm{L})$ (21331020, Life Technologies) supplemented with $10 \%$ of Fetal Bovine Serum (10270106/A3381E, Life Technologies) and 1\% Penicillin/Streptomycin (15140122, Life Technologies) and incubation at $37^{\circ} \mathrm{C}$ for $24 \mathrm{~h}$ in a humidified atmosphere containing $5 \% \mathrm{CO}_{2}$.

\subsection{Schwann cells culture}

Culture of rat Schwann cells (SCs; P10301, Innoprot) for 5 days ( $n=3$ per group) was performed on NF (PLA-18.2\% PPy) and MF (PLA3.5\% PPy) substrates in order to study the cell adhesion and proliferation of glial cells.

After the expansion of the SCS in a cell culture flask, they were washed with PBS and a trypsin/EDTA solution (T/E; 25200-072, Life Technologies) was then added to break the cell-matrix and cell-cell interactions in order to remove the cells from the bottom of the culture bottle. After centrifugation at $1080 \mathrm{rpm}$ for $5 \mathrm{~min}$, the pellet was resuspended in Schwann cell culture medium (P60123, Innoprot). At this moment, the seeding with SCs in passage 7 was performed with a seeding density of 100.000 cells per substrate. Finally, the culture was introduced in an incubator at $37{ }^{\circ} \mathrm{C}$ with a humid atmosphere containing $5 \% \mathrm{CO}_{2}$ for 5 days, renewing the Schwann cell culture medium every $48 \mathrm{~h}$.

\subsection{Dorsal root ganglia culture}

DRG from E10 chick embryos ( $n=5$ per group) were cultivated during 3 days on NF (PLA-18.2\% PPy) and MF (PLA-3.5\% PPy) substrates in order to study the axonal extension on both types of substrates.

DRG were grown for 3 days in Ham F12 culture medium (11765054, Thermo Fisher Scientific) with 1\% HEPES 1M (15630049, Thermo Fisher Scientific), 1\% L-Glutamine 200 mM (25030024, Thermo Fisher Scientific), 1\% N2 supplement (17502048, Thermo Fisher Scientific), 1\% Penicillin/Streptomycin (15140122, Life Technologies) and $10 \mathrm{ng} / \mathrm{mL}$ of nerve growth factor (NGF) (13257019, Thermo Fisher Scientific).

\subsection{Immunostaining of SCS and DRG}

For the immunostaining, after removing the cell medium and washing the materials with PBS, cells were fixed with $4 \%$ paraformaldehyde (PFA; 47608, Sigma-Aldrich) for $20 \mathrm{~min}$ at room temperature. After cell fixation, 3 washes of 10 min with DPBS were performed to remove PFA residues. At this point, the non-specific bindings were blocked and the cell membrane was permeabilized by the use of a blocking buffer composed of DPBS with 3\% bovine serum albumin (BSA; A7906, Sigma-Aldrich) and 0.1\% Tween20 (P1379, SigmaAldrich) for $1 \mathrm{~h}$ at room temperature.

On the one hand, SCs were stained with FITC-phalloidin (B607, Life Technologies) at a 1/200 dilution to mark the cytoskeleton actin filaments (green colour) and with DAPI (D9564, Sigma-Aldrich) at a 1/1000 dilution for 10 min to mark the cells' nuclei (blue colour). The imaging was performed using a confocal microscope (LEICA TCS SP5, Leica microsystems). 
On the other hand, DRG were stained with TUJ-1 (neuron-specific class III beta-tubulin, Neuromics, MO15013) at a 1/500 dilution in green colour. The imaging was performed using a MacroFluo Fluorescence Magnifier (MZZ16F, Leica microsystems) with Digital Camera (DFC300 FX, Leica microsystems).

\subsection{Quantification of axonal extension and axonal sprouting}

In order to quantify the axonal extension, two different parameters were obtained (Fig. 1). On the one hand, the maximum length of axons was measured as the distance between the edge of the DRG body and the end of the longest axon (maximum of both sides and sum of both sides). On the other hand, the area of axons was obtained by subtracting the area of the DRG body from the total area of the DRG. Both parameters were measured using the ImageJ/FIJI image processing software [54].
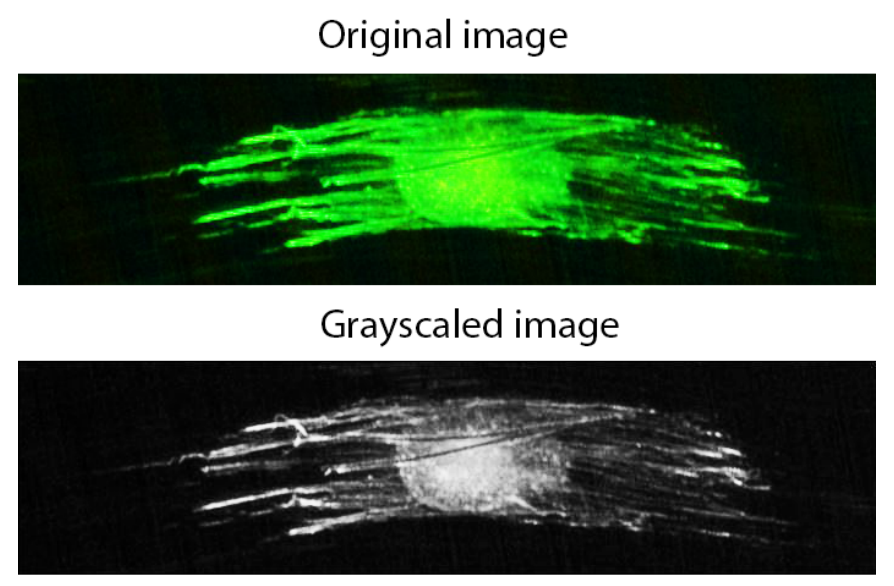

Total area of the DRG
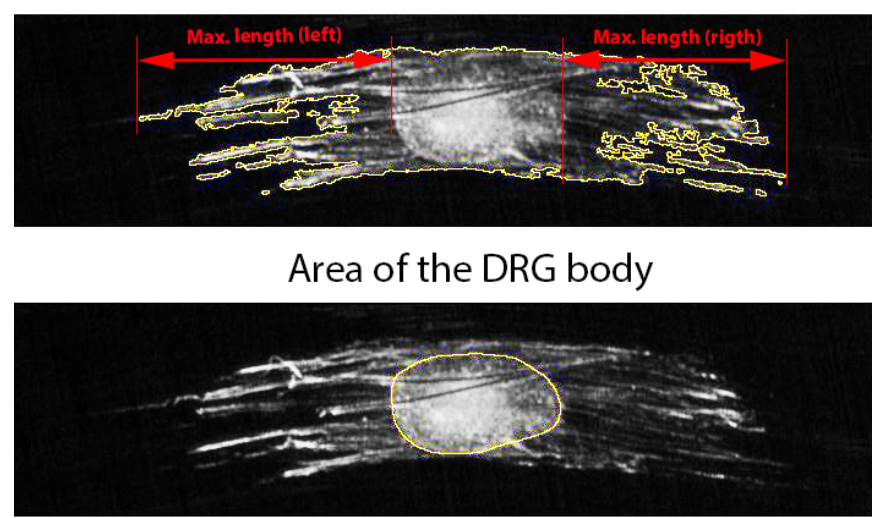

Fig. 1. Different steps for the quantification of axonal extension of DRG. The maximum length of axons was calculated as the maximum value of both sides and the sum of both sides. The area of axons was obtained by subtracting the area of the DRG body from the total area of the DRG.

The DRG images were also processed and analysed using an in-house software developed under MATLAB R2018a (The MathWorks, Inc.) to quantify the axonal sprouting (Fig. 2). All images of DRG stained with TUJ-1 were cropped to the region of interest and grey scaled. The grey intensity value (0-256) of all pixels in each transversal section ( $Y$-axis, image height) was measured and, thus, the mean value was calculated for each section. The mean data from images were normalized (up to 1) considering 0 and 1 the lowest and highest grey intensity values of the entire image, respectively. The centre of the DRG was obtained as the maximum point of the relative intensity. By representing the relative intensity gradient, the left and right edges of the DRG body were obtained as the maximum and minimum values of the gradient respectively within a window of values.

Once the centre and edges of the DRG body were marked, three different parameters were obtained to measure axonal sprouting: $S_{\text {centre }}$ as the distance between the point that corresponds to the relative intensity of the centre of the DRG body ( $\left.I_{\text {centre }}\right)$ and the point where $I_{\text {centre }}$ is reduced by $75 \%\left(\frac{I_{\text {centre }}}{4}\right)$ (Eq. (8)), Sedge as the distance between the point that corresponds to the relative intensity of the edge of the DRG body (l edge$)$ and the point where $l_{\text {edge }}$ is reduced by $75 \%\left(\frac{I_{\text {edge }}}{4}\right)$ (Eq. (9)) and $S_{\text {AUc }}$ as the area under the curve (AUC) between the point that corresponds to the relative intensity of the edge of the DRG body $\left(l_{\text {edge }}\right)$ and the point where $I_{\text {centre }}$ is reduced by $80 \%\left(\frac{I_{\text {centre }}}{5}\right)$ (Eq. (10)). The three parameters were obtained for both the left and right sides and the sum of both values was considered. 
$S_{\text {centre }}=$ Distance $\left(I_{\text {centre }}, \frac{I_{\text {centre }}}{4}\right)$

$S_{\text {edge }}=$ Distance $\left(I_{\text {edge }}, \frac{I_{\text {edge }}}{4}\right)$

$S_{\text {AUC }}=\operatorname{Area}\left(I_{\text {edge }}, \frac{I_{\text {centre }}}{5}\right)$
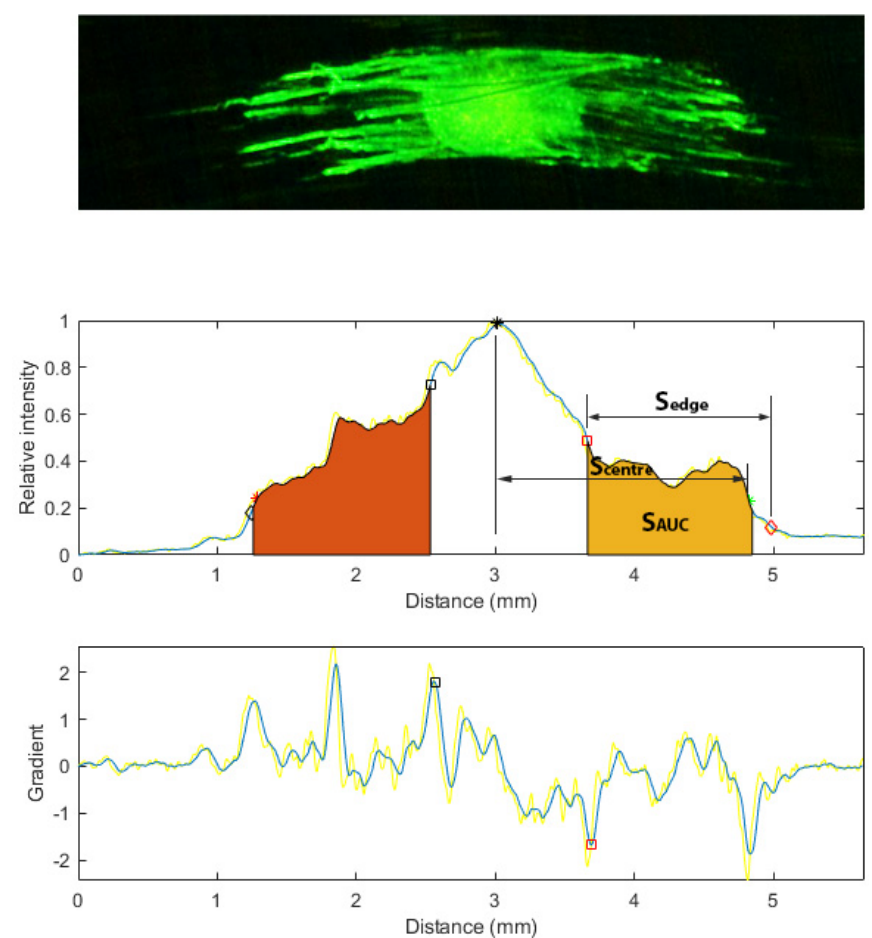

Fig. 2. Quantification of axonal sprouting from DRG bodies using the relative intensity of the images. The edges of DRG bodies were obtained using the

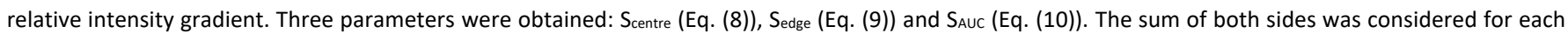
parameter.

\subsection{Statistical analysis}

Results were expressed as mean \pm standard deviation (SD) or as mean \pm standard error of the mean (SEM). The statistical analysis of the results was performed with GraphPad Prism ${ }^{\circledR}$ software using the one-way ANOVA test together with a multiple sample mean comparison (Tuckey's multiple comparisons test with a significance degree of 95\%) in order to reveal significant differences between conditions. Statistically significant differences are indicated by $*, * *, * * *$ or $* * * *$, indicating a p-value below $0.05,0.01,0.001$ or 0.0001 respectively.

\section{Results and discussion}

\subsection{Characterization of NF and MF substrates}

On the one hand, macroscopic images of NF and MF substrates are shown in Fig. 3, before and after the PPy coating using the coating protocol C2. On the other hand, microscopic images of NF and MF substrates are shown in Fig. S1 and Fig. 4, before and after the PPy coating using the coating protocols $\mathrm{C} 1$ and $\mathrm{C} 2$, respectively.

When the coating protocol C1 was employed (Fig. S1), the PPy coating presented several areas where the PPy coating failed to completely cover the fibres, so some parts of the PLA fibres were visible. In addition, the PPy coating had a granular appearance, which indicates that the different PPy grains have not come together to form a continuous layer. All this is indicative of a less homogeneous coating, without forming a continuous layer of PPy in all fibres for the coating protocol C1. However, when the coating protocol $\mathrm{C} 2$ is employed (Fig. 4), FESEM images of NF (Fig. 4 C, D) and MF (Fig. 4 G, H) substrates showed a smooth surface, without non-covered areas and without the grainy appearance that was observed for the coating protocol $\mathrm{C} 1$. Therefore, with the coating protocol $\mathrm{C} 2$ a continuous 
(without interruptions or bald spots) and homogeneous (with a uniform coating thickness and without PPy aggregates) PPy coating is obtained.
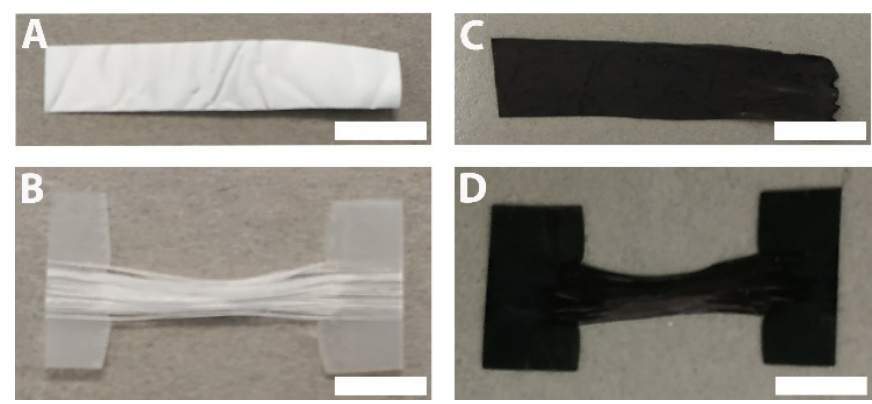

Fig. 3. Macroscopic images of PLA and PLA-PPy substrates before and after the PPy coating using the coating protocol C2. A: PLA NF mat. B: PLA MF bundle. C: PLA-PPy NF mat. D: PLA-PPy MF bundle. At the extremes of the MF bundles ( $B$ and D) the auxiliary PCL bands that act as fasteners and hold MFs together can be observed. Scale bar $=5 \mathrm{~mm}$.

The mass fraction of PPy for NF and MF substrates coated following the coating protocol C2 was of $18.2 \%$ and $3.5 \%$, respectively. Therefore, for the same coating protocol, more PPy was deposited in NF substrates due to their higher surface area and number of fibres $\left(\frac{S_{N F}}{S_{M F}}=4.8 \pm 0.2 ; \frac{n_{N F}}{n_{M F}}=97 \pm 4\right)$, with a higher mass fraction of PPy for NF substrates (Table 2). The effective coating thickness of PPy $(e)$ was higher for MF substrates, with a ratio between NF and MF substrates $\left(\frac{e_{N F}}{e_{M F}}\right)$ of 0.21 , that was obtained by applying Eq. (11) in the case of substrates with the same mass and length $\left(m_{N F}=m_{M F}, L_{N F}=L_{M F}\right)$.

$\frac{m_{N F}}{m_{M F}}=\frac{V_{N F} \cdot \rho_{P P y}}{V_{M F} \cdot \rho_{P P y}}=\frac{2 \cdot \pi \cdot r_{N F} \cdot e_{N F} \cdot L_{N F} \cdot n_{N F} \cdot \rho_{P P y}}{2 \cdot \pi \cdot r_{M F} \cdot e_{M F} \cdot L_{M F} \cdot n_{M F} \cdot \rho_{P P y}}$

The electric characterization (Table 2) showed that, for the same type of substrate, the greater the mass fraction of PPy the greater the conductivity of the material. For the same coating protocol, similar conductivities were obtained for NF and MF substrates. However, for the same mass fraction of PPy, MF substrates reached higher conductivities due to the lower tortuosity of the path that electric charges must travel, with fewer interfaces. The smaller values obtained for $\sigma_{D C P P y}$ when using NF substrates are indicative of this tortuosity of the path.

The ratio between the $\omega_{P P y} / S$ values for NFs and MFs showed values close to 1 for both coating protocols, which is indicative that a homogeneous coating is obtained with few aggregates. However, the high standard deviation obtained for the coating protocol $\mathrm{C} 1$ is indicative of a less homogeneous PPy coating which is corrected when the coating protocol C2 is used. This, along with the higher electrical conductivities obtained for the coating protocol C2 led us to choose the substrates coated with this protocol for the following biological characterization of the substrates.

\subsection{Schwann cells culture}

The culture of SCs (Fig. 5) showed that the cells were capable of adhering and proliferating in both NF and MF substrates without needing a previous coating of cell adhesive proteins or peptides. The cells were able to completely cover the substrates, without observing a notable difference when PPy was present.

On the one hand, SCs seeded on NF substrates (Fig. 5 A, B and C) presented a very aligned cytoskeleton, clearly oriented in the direction of NFs. Thus, the further expansion of their cytoskeleton takes place preferentially along the direction of the fibril axis, resulting in a highly elongated shape of each cell. The cytoskeleton of the cells presented a high aspect ratio, indicative of a strong cell-material interaction. The cell's cytoplasm wrapped and followed some particular NF, without other cells above it and without connecting other contiguous NFs. Therefore, the use of NFs entailed a higher cell-fibre interaction with a high actin cytoskeleton polarization of the cells, presenting a stretched morphology in the direction of the fibres. This intimate relationship between the cells and the substrate entails a weaker cell-cell interaction and a smaller motility of SCs, as previously observed for electrospun substrates with a small diameter of NFs $[19,21]$. 


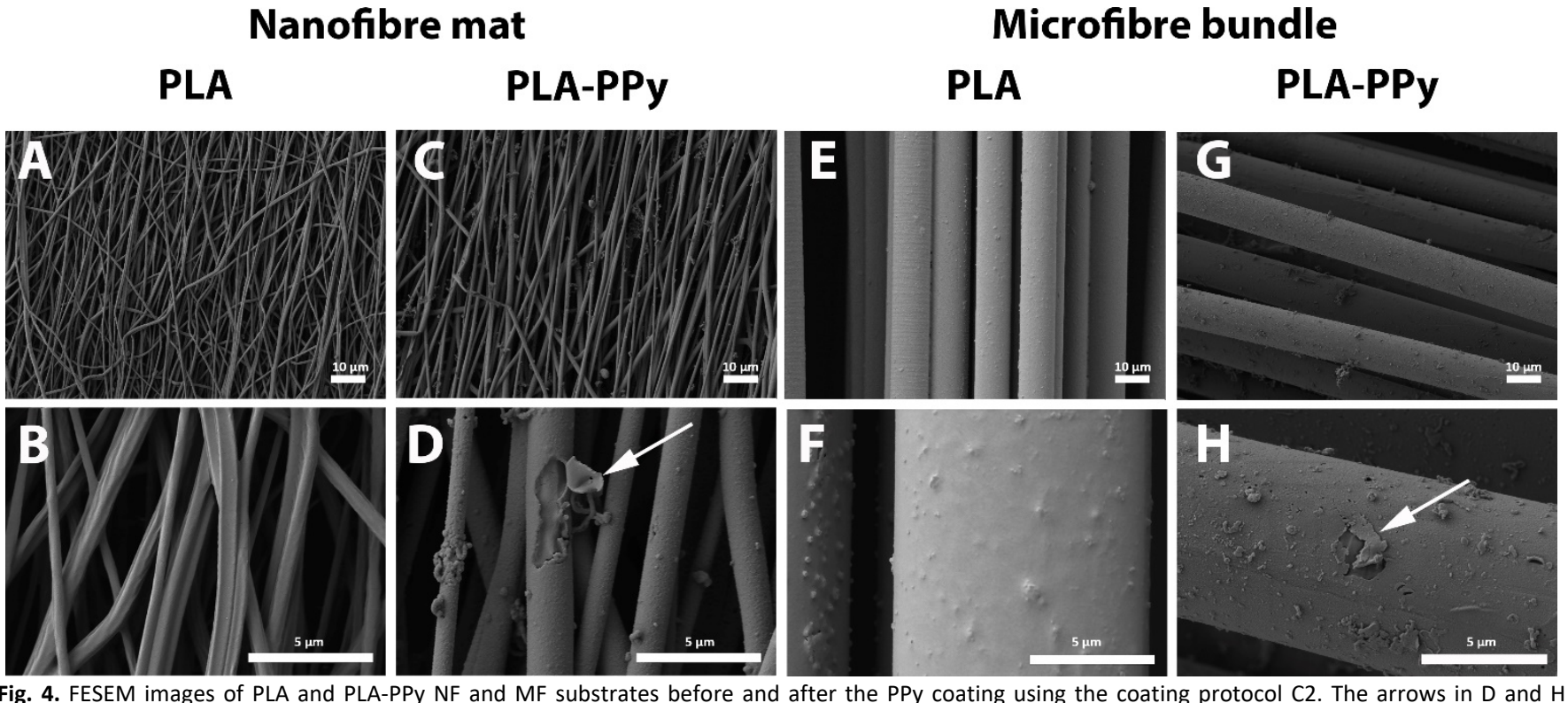

Fig. 4. FESEM images of PLA and PLA-PPy NF and MF substrates before and after the PPy coating using the coating protocol C2. The arrows in D and $H$ indicate a peeling of the PPy coating allowing its visual appreciation. Scale bar $=10 \mu \mathrm{m}(\mathrm{A}, \mathrm{C}, \mathrm{E}, \mathrm{G})$ and $5 \mu \mathrm{m}(\mathrm{B}, \mathrm{D}, \mathrm{F}, \mathrm{H})$.

\section{Table 2}

Physical and electric characterization of PLA-PPy NF and MF substrates. The mass fraction of PPy $\left(\omega_{P P y}\right)$, the effective coating thickness of PPy $(e)$, the DCconductivity of substrates $\left(\sigma_{D C}\right)$ and the DC-conductivity of PPy $\left(\sigma_{D C} P P y\right)$ were obtained for MF and NF substrates. Values are expressed as mean \pm SD.

\begin{tabular}{|c|c|c|c|c|c|c|c|c|c|}
\hline \multirow{2}{*}{$\begin{array}{l}\text { Coating } \\
\text { protocol }\end{array}$} & \multicolumn{4}{|c|}{ Microfibre bundle } & \multicolumn{4}{|c|}{ Nanofibre mat } & \multirow{2}{*}{$\frac{\omega_{P P y N F} / S_{N F}}{\omega_{P P y M F} / S_{M F}}$} \\
\hline & $\omega_{P P y}(\%)$ & e (nm) & $\sigma_{D C}(\mathrm{~S} / \mathrm{m})$ & $\sigma_{D C P P y}(\mathrm{~S} / \mathrm{m})$ & $\omega_{P P y}(\%)$ & e (nm) & $\sigma_{D C}(\mathrm{~S} / \mathrm{m})$ & $\sigma_{D C P P y}(\mathrm{~S} / \mathrm{m})$ & \\
\hline C1 & $0.9 \pm 0.2$ & $28 \pm 5$ & $0.012 \pm 0.003$ & $23 \pm 5$ & $4 \pm 2$ & $5 \pm 2$ & $0.0012 \pm 0.0005$ & $0.08 \pm 0.05$ & $0.9 \pm 0.7$ \\
\hline C2 & $3.5 \pm 0.7$ & $122 \pm 8$ & $1.36 \pm 0.08$ & $590 \pm 35$ & $18.2 \pm 0.7$ & $25 \pm 2$ & $1.4 \pm 0.4$ & $21 \pm 4$ & $1.1 \pm 0.3$ \\
\hline
\end{tabular}

On the other hand, the cytoskeleton of SCs seeded on MF substrates (Fig. 5 D, E and F) did not present any clear orientation and are much less polarised. This results in a way of adhesion more spread of each cell, with much less polarized shape than in the case of nanofibres. As can be observed, the cells presented a more spread cytoskeleton because they were wrapping much bigger fibres and, therefore, they had a much bigger smooth surface for growing radially. In addition, as can be observed in Fig. $5 \mathrm{E}$ and $\mathrm{F}$, the nuclei of cells seeded on MFs are much closer to each other, often overlapping. This, together with the greater thickness of the cell mat in the case of MF substrates ( $26 \mu \mathrm{m}$ and $38 \mu \mathrm{m}$ for images $5 \mathrm{E}$ and $\mathrm{F}$ versus $8 \mu \mathrm{m}$ and $10 \mu \mathrm{m}$ for images $5 \mathrm{~B}$ and $\mathrm{C}$ ), indicates that cells are arranged in stacks, forming multilayers of cells. Therefore, there is an increase of cell-cell interactions, providing a greater freedom of movement for the cells and, therefore, a greater motility and ability to reorganize than in the case of NFs. For this reason, many cells presented a cytoskeleton that was connecting 

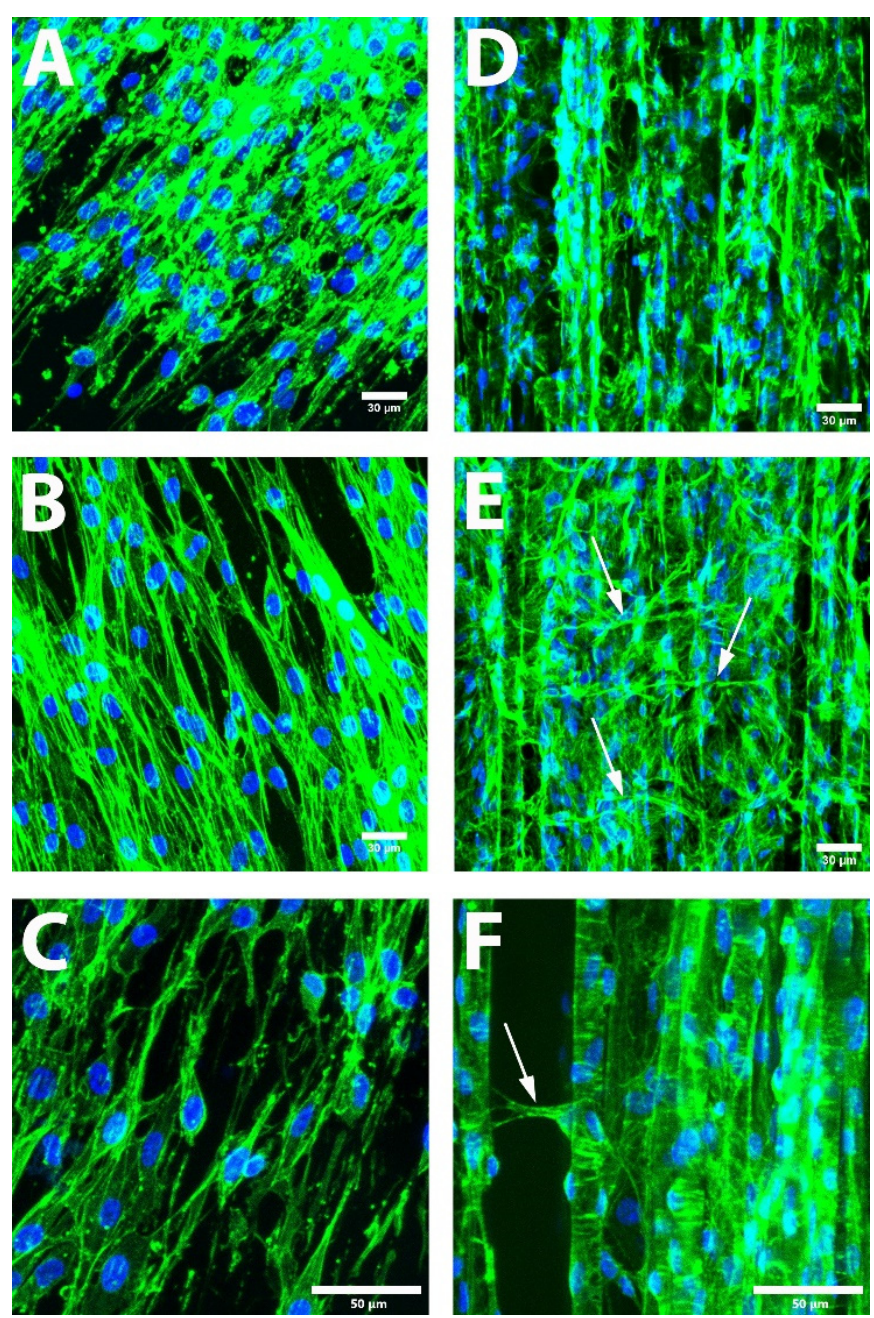

Fig. 5. Images of SCs after being cultured for 5 days on PLA NF mat (A), PLA-PPy NF mat (B), PLA MF bundle (D) and PLA-PPy MF bundle (E). C and F show detail images of PLA-PPy NF mat and MF bundle, respectively. Cells seeded on NF substrates presented an aligned cytoskeleton in the direction of NFs, while cells seeded on MF substrates did not present a clear orientation, connecting with contiguous MFs (see arrows in E and F). Scale bar $=30 \mu \mathrm{m}(\mathrm{A}, \mathrm{B}, \mathrm{D}, \mathrm{E})$ and $50 \mu \mathrm{m}(\mathrm{C}, \mathrm{F})$.

with other contiguous MFs, growing perpendicular to the direction of the MFs (see arrows in Fig. $5 \mathrm{E}$ and F).

It has been previously observed that cells respond to different physical signals derived of the local geometry of the substrates where they are seeded [55-57]. One of these signals is the substrate curvature, which has a direct effect on the cell's mechanoreceptors [55]. It has been observed that the substrate curvature plays a key role on the cells spreading area, the actin cytoskeleton organization, the focal adhesion points, the filopodia formation and the cell motility and migration [19,21]. As previously reported in the case of electrospun NFs, increasing the diameter of the fibres that form the substrate entails a decrease of actin cytoskeleton organization and fewer focal adhesion points $[19,21]$. This can be related to the lower organization and alignment of the SCs cytoplasms when MFs were used. In addition, it has also been observed that increasing the fibre diameter in the case of electrospun NFs enhances filopodia formation and increases cell motility and migration [19,21], which can explain the increased cell-cell interactions when MF substrates were used. This is of great importance for axonal extension from DRG because, as previously reported [58,59], SCs first migrate, and then the axons grow and extend on top of the SCs. Therefore, it is critical to use a substrate that enhances the motility and accelerates the migration of SCs in order to speed up the axonal extension from DRG. This is in accordance with previous studies carried out on electrospun NFs, were a higher SCs migration from DRG was observed when the larger diameters were used, with a direct correlation with axonal extension [19,21].

It was thus shown that aligned NF substrates could guide SCs migration directedly and with a strong cell-biomaterial association, at the price of reducing the freedom of movement and the migration speed of cells. When using MFs with a higher radius of curvature, the cell's freedom of movement and the cell-cell associations were increased, and the SC had a less polarized cytoskeleton. This increased freedom of movement and motility observed on SCs seeded on MF substrates is critical in order to accelerate the SCs migration from the DRG body and, therefore, to speed up the axonal extension from DRG (see section 3.3). 


\subsection{Quantification of axonal extension and axonal sprouting}

To further verify the potential of aligned NF and MF substrates on neuronal cells, DRG were isolated and cultured on four different substrates: PLA and PLA-PPy NF mats; PLA and PLA-PPy MF bundles. TUJ-1 immunofluorescence images of DRG after 3 days of culture on the different substrates are shown in Fig. 6 . As can be observed, the neurites were extended from DRG bodies following the uniaxial alignment of the fibres.

After the quantification of the maximum length and area of axons (Fig. 7) we observed an increased axonal extension for MF substrates. On the one hand, for PLA MF substrates the maximum length of axons (sum of both sides) increased by a factor of 2.1 and the area of axons increased by a factor of 2.74 versus PLA NF substrates. On the other hand, for PLA-PPy MF substrates the maximum length of axons (sum of both sides) increased by a factor of 2.77 and the area of axons increased by a factor of 3.26 versus PLA-PPy NF substrates.
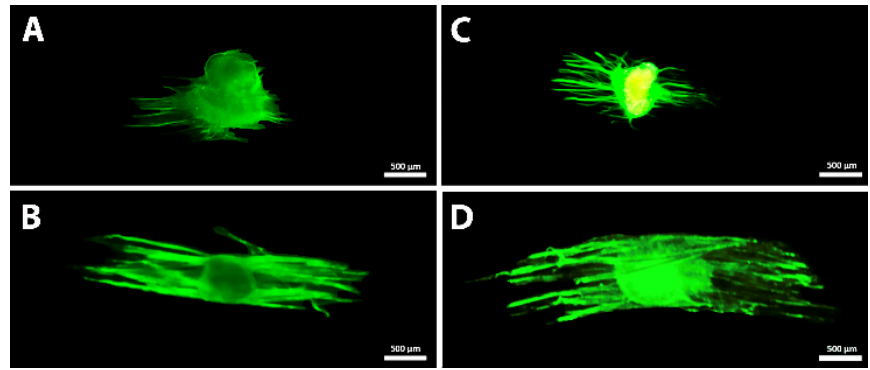

Fig. 6. Images of DRG after being cultured for 3 days on PLA NF mat (A), PLA MF bundle (B), PLA-PPy NF mat (C) and PLA-PPy MF bundle (D). A clear alignment of the axons can be observed in the direction of the fibres, with a higher axonal extension and sprouting when MF substrates were used. Scale bar $=500 \mu \mathrm{m}$.
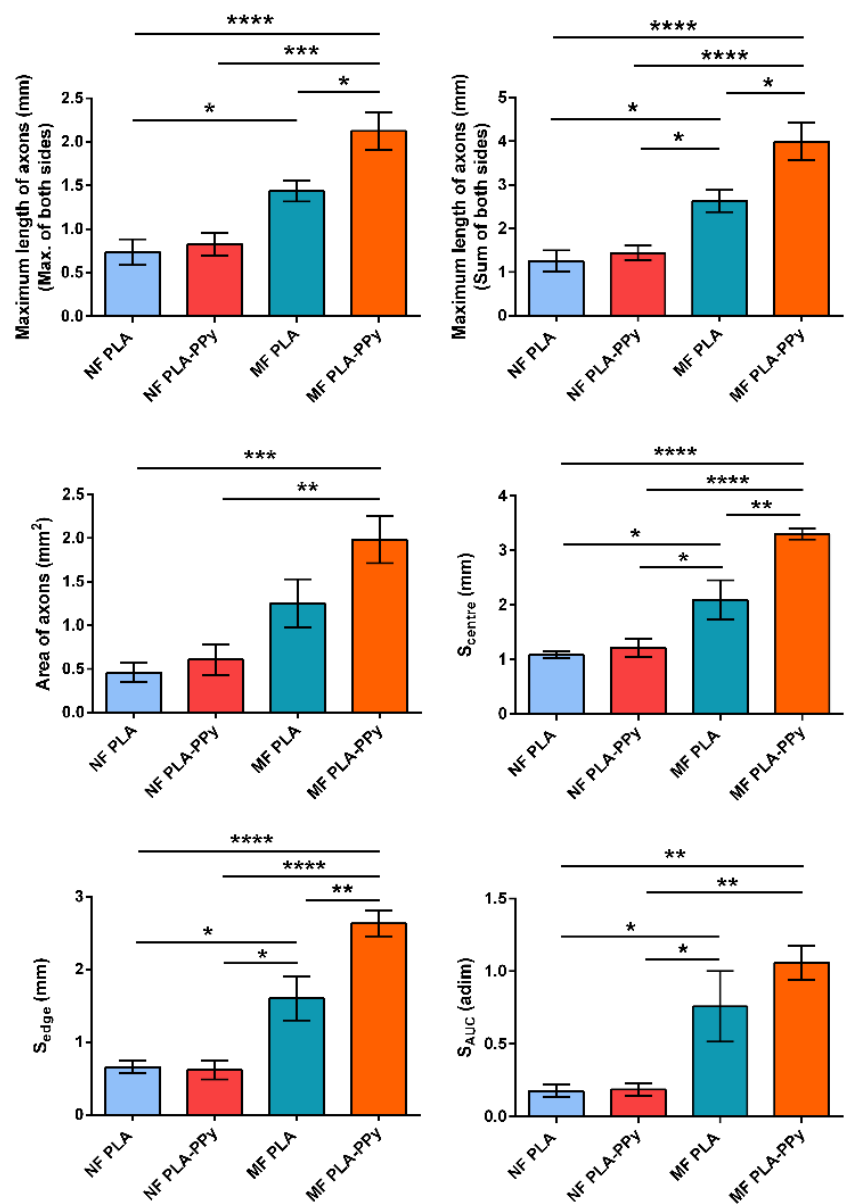

Fig. 7. Quantification of axonal extension (maximum length of axons and area of axons) and axonal sprouting ( $\mathrm{S}_{\text {centre, }} \mathrm{S}_{\text {edge }}$ and $\mathrm{S}_{\mathrm{Auc}}$ ) on different substrates after 3 days of DRG culture. The use of MF substrates enhances both axonal extension and axonal sprouting. In addition, the PPy coating additionaly enhances axonal extension and axonal sprouting when MFs are used. Values are expressed as mean \pm SEM. 
Regarding axonal sprouting, three different parameters ( $\mathrm{S}_{\text {centre, }} \mathrm{S}_{\text {edge }}$ and $\mathrm{S}_{\mathrm{AUC}}$ ) were measured to quantify the growth and density of axons. When MF substrates were used, a clear increase in all the parameters was observed (Fig. 7), which increased by a factor of 2.71, 4.27 and 5.67 for $S_{\text {centre, }} S_{\text {edge }}$ and $S_{A U C}$, respectively, when PLA-PPy MF substrates were used instead of PLA-PPy NF substrates. Therefore, the axon density of neurons from the DRG was higher on PLA and PLA-PPy MF substrates than on PLA and PLA-PPy NF substrates, with a higher spreading area (Fig. 7).

The presence of the PPy coating did not make a statistically significant difference when using NF substrates. However, when MF substrates were used, an increase in all the measured parameters could be observed when PPy was present, becoming statistically significant for the maximum length of axons, $\mathrm{S}_{\text {centre }}$ and $\mathrm{S}_{\text {edge. }}$. This may be due to the greater surface roughness of the PPy-coated MF substrates, which could favour the DRG adhesion.

The greater axonal growth when MF substrates are used may be directly related to a greater and accelerated migration of SCs from the DRG body. It has been previously reported for electrospun NF substrates that an increase in the diameter of NFs entails a higher motility and migration capacity of SCs $[19,21]$. This accelerated migration of SCs on microfibre-based substrates is of great importance to speed up axonal extension because, as it has been reported [58,59], the formation of a cellular tapestry on the substrate made by migrating SCs is a necessary prerequisite for axonal extension from the DRG body. Sprouting and extension from the DRG body takes place always accompanied by Scs. It has been previously reported that, in the case of electrospun NFs, the migration distance of SCs from the DRG increases when increasing the diameter of the fibres [19,21]. In addition, it was observed that this migration distance of SCs is directly related to the neurite length, observing an enhanced axon outgrowth when increasing the fibre diameter.

In accordance with the results obtained in section 3.2, the use of MF substrates plays a key role in order to increase the cell's freedom of movement and the cell-cell interactions, which enhances the axonal growth from DRG. The SCs seeded on the NF substrates present a high cell-biomaterial interaction without forming cell stacks, which entails a lower cell motility and migration capacity as well as a fewer number of cells able to interact with the axons. The SCs seeded on MF substrates, by contrast, have a more dynamic behaviour, forming cell layers with cell-cell interactions dominating over cell-material interactions. This entails a greater ability to reorganize and a higher availability of cells, which can associate with the growing axons, thus increasing the interactions between SCs and axons, which is critical in order to accelerate axonal growth. Therefore, the higher freedom for rearrangement that the migrated SCs have on the MF substrate entails more interactions between SCs and axons, which is critical to enhance axonal growth and survival. With that, we have found an indirect effect of the fibre radii on axonal extension, through the different constraining effect they have on the SCs adhesion configuration on the fibres.

\section{Conclusions}

Our experimental data demonstrate the ability to obtain poly(lactic acid)-polypyrrole electrically conductive, biodegradable and biocompatible substrates that can be used in neural tissue engineering for implantable devices applications.

The different biological behaviour of SCs seeded on highly aligned PLA-PPy substrates which differed in diameter have been studied. On nanosized fibres (500 nm diameter) we find that single SCs can completely embrace and surround the circumference of each fibril. By contrast, on microsized fibres (10 $\mu \mathrm{m}$ diameter) the SCs cannot embrace the fibre circumference: the effective curvature radius of the substrate on which they adhere is much larger than in the case of the nanofibrils. Moreover, on microsized fibres the cells can stack on top of each other, probably because their mobility is much less hindered than when they are completely embracing the circumference of nanofibres. Therefore, whereas on NFs the SCs interact essentially with the fibre surface, on MFs we find the cell-fibre but also many cellcell interactions.

This circumstance seems to be proactive for the extension of axons from the neurons when the DRG explants are seeded on the substrates. We find that axons extend more rapidly and for larger distances on the microfibered substrate than on the nanofibered ones. We think this is related to the higher migration speed of SCs from the DRG body, since the higher motility that SCs have on the MF substrate accelerates this migration, which is directly related to the axonal extension since it is well known that this extension is accompanied by SCs.

The PPy coating of the PLA substrates resulted in an additional promoting effect on axonal growth, possibly produced by the greater surface roughness that favours the adhesion of the DRG. In addition, the electroconductive coating of the substrates allows its future electrical stimulation to enhance the axonal growth.

\section{CRediT authorship contribution statement}

Fernando Gisbert Roca: Methodology, Software, Formal analysis, Investigation, Writing - Original Draft, Visualization. Jorge Más Estellés: Writing - Review \& Editing, Supervision, Funding acquisition. Manuel Monleón Pradas: Conceptualization, Writing - Review \& Editing, Supervision, Funding acquisition. Cristina Martínez-Ramos: Conceptualization, Methodology, Writing - Review \& Editing, Supervision, Funding acquisition. 


\section{Conflicts of interest}

There are no conflicts to declare.

\section{Acknowledgements}

The authors acknowledge financing from the Spanish Government's State Research Agency (AEI) through projects DPI2015-72863-EXP and RTI2018-095872-B-C22/ERDF. FGR acknowledges scholarship FPU16/01833 of the Spanish Ministry of Universities. We thank the Electron Microscopy Service at the UPV, where the FESEM images were obtained.

\section{References}

[1] E. a Huebner, S.M. Strittmatter, Axon Regeneration in the Peripheral and Central Nervous Systems, Results Probl. Cell Differ. 48 (2009) 339-351. https://doi.org/10.1007/400_2009_19.

[2] K.S. Houschyar, A. Momeni, M.N. Pyles, J.Y. Cha, Z.N. Maan, D. Duscher, O.S. Jew, F. Siemers, J. van Schoonhoven, K.S. Houschyar, A. Momeni, M.N. Pyles, J.Y. Cha, Z.N. Maan, D. Duscher, O.S. Jew, F. Siemers, J. van Schoonhoven, The Role of Current Techniques and Concepts in Peripheral Nerve Repair, Plast. Surg. Int. 2016 (2016) 1-8. https://doi.org/10.1155/2016/4175293.

[3] W. Daly, L. Yao, D. Zeugolis, A. Windebank, A. Pandit, A biomaterials approach to peripheral nerve regeneration: Bridging the peripheral nerve gap and enhancing functional recovery, J. R. Soc. Interface. 9 (2012) $202-221$. https://doi.org/10.1098/rsif.2011.0438.

[4] G.C.W. de Ruiter, M.J.A. Malessy, M.J. Yaszemski, A.J. Windebank, R.J. Spinner, Designing ideal conduits for peripheral nerve repair., Neurosurg. Focus. 26 (2009) E5. https://doi.org/10.3171/FOC.2009.26.2.E5.

[5] M.D. Tang-Schomer, 3D axon growth by exogenous electrical stimulus and soluble factors, Brain Res. 1678 (2018) $288-296$. https://doi.org/10.1016/j.brainres.2017.10.032.

[6] M.D. Sarker, S. Naghieh, A.D. McInnes, D.J. Schreyer, X. Chen, Regeneration of peripheral nerves by nerve guidance conduits: Influence of design, biopolymers, cells, growth factors, and physical stimuli, Prog. Neurobiol. 171 (2018) 125-150. https://doi.org/10.1016/j.pneurobio.2018.07.002.

[7] I.A. Kim, S.A. Park, Y.J. Kim, S.H. Kim, H.J. Shin, Y.J. Lee, S.G. Kang, J.W. Shin, Effects of mechanical stimuli and microfiber-based substrate on neurite outgrowth and guidance, J. Biosci. Bioeng. 101 (2006) 120-126. https://doi.org/10.1263/jbb.101.120.

[8] A.W. English, G. Schwartz, W. Meador, M.J. Sabatier, A. Mulligan, Electrical stimulation promotes peripheral axon regeneration by enhanced neuronal neurotrophin signaling, Dev. Neurobiol. 67 (2007) 158-172. https://doi.org/10.1002/dneu.20339.

[9] C.E. Schmidt, V.R. Shastri, J.P. Vacanti, R. Langer, Stimulation of neurite outgrowth using an electrically conducting polymer, Proc. Natl. Acad. Sci. U. S. A. 94 (1997) 8948-8953. https://doi.org/10.1073/pnas.94.17.8948.

[10] J. Huang, Z. Ye, X. Hu, L. Lu, Z. Luo, Electrical stimulation induces calcium-dependent release of NGF from cultured Schwann cells, Glia. 58 (2010) 622-631. https://doi.org/10.1002/glia.20951.

[11] P.M. Tsimbouri, L.E. McNamara, E. V. Alakpa, M.J. Dalby, L.A. Turner, Cell-Material Interactions, Second Edi, Elsevier Inc., 2014. https://doi.org/10.1016/B978-0-12-420145-3.00007-9.

[12] H. Amani, H. Arzaghi, M. Bayandori, A.S. Dezfuli, H. Pazoki-Toroudi, A. Shafiee, L. Moradi, Controlling Cell Behavior through the Design of Biomaterial Surfaces: A Focus on Surface Modification Techniques, Adv. Mater. Interfaces. 6 (2019) 1-30. https://doi.org/10.1002/admi.201900572.

[13] W. Zhu, F. Masood, J. O'Brien, L.G. Zhang, Highly aligned nanocomposite scaffolds by electrospinning and electrospraying for neural tissue regeneration, Nanomedicine Nanotechnology, Biol. Med. $11 \quad$ (2015) 693-704. https://doi.org/10.1016/j.nano.2014.12.001.

[14] Y.S. Lee, G. Collins, T. Livingston Arinzeh, Neurite extension of primary neurons on electrospun piezoelectric scaffolds, Acta Biomater. 7 (2011) 3877-3886. https://doi.org/10.1016/j.actbio.2011.07.013.

[15] J.Y. Lee, C.A. Bashur, A.S. Goldstein, C.E. Schmidt, Polypyrrole-coated electrospun PLGA nanofibers for neural tissue applications, Biomaterials. 30 (2009) 4325-4335. https://doi.org/10.1016/j.biomaterials.2009.04.042.

[16] Y. Wang, Z. Zhao, B. Zhao, H. xu Qi, J. Peng, L. Zhang, W.J. Xu, P. Hu, S.B. Lu, Biocompatibility evaluation of electrospun aligned poly(propylene carbonate) nanofibrous scaffolds with peripheral nerve tissues and cells in vitro, Chin. Med. J. (Engl). 124 (2011) 2361-2366. https://doi.org/10.3760/cma.j.issn.0366-6999.2011.15.020.

[17] Y. Zou, J. Qin, Z. Huang, G. Yin, X. Pu, D. He, Fabrication of Aligned Conducting PPy-PLLA Fiber Films and Their Electrically Controlled Guidance and Orientation for Neurites, ACS Appl. Mater. Interfaces. 8 (2016) 12576-12582. https://doi.org/10.1021/acsami.6b00957.

[18] Y. Xu, Z. Huang, X. Pu, G. Yin, J. Zhang, Fabrication of Chitosan/Polypyrrole-coated poly(L-lactic acid)/Polycaprolactone aligned fibre films for enhancement of neural cell compatibility and neurite growth, Cell Prolif. 52 (2019) 1-11. https://doi.org/10.1111/cpr.12588.

[19] H.B. Wang, M.E. Mullins, J.M. Cregg, C.W. McCarthy, R.J. Gilbert, Varying the diameter of aligned electrospun fibers alters neurite outgrowth and Schwann cell migration, Acta Biomater. 6 (2010) 2970-2978. https://doi.org/10.1016/j.actbio.2010.02.020.

[20] G.T. Christopherson, H. Song, H.Q. Mao, The influence of fiber diameter of electrospun substrates on neural stem cell differentiation and proliferation, Biomaterials. 30 (2009) 556-564. https://doi.org/10.1016/j.biomaterials.2008.10.004.

[21] S. Gnavi, B.E. Fornasari, C. Tonda-Turo, G. Ciardelli, M. Zanetti, S. Geuna, I. Perroteau, The influence of electrospun fibre size on 
Schwann cell behaviour and axonal outgrowth, Mater. Sci. Eng. C. 48 (2015) 620-631. https://doi.org/10.1016/j.msec.2014.12.055.

[22] N. Bhardwaj, S.C. Kundu, Electrospinning: A fascinating fiber fabrication technique, Biotechnol. Adv. 28 (2010) $325-347$. https://doi.org/10.1016/j.biotechadv.2010.01.004.

[23] S. Agarwal, J.H. Wendorff, A. Greiner, Use of electrospinning technique for biomedical applications, Polymer (Guildf). 49 (2008) 5603-5621. https://doi.org/10.1016/j.polymer.2008.09.014.

[24] T. Karthik, Novel properties of PLA fibers, Synth. Fibres. 33 (2004) 5-10. https://doi.org/10.1177/15589250010s-01000308.

[25] A. Markus, T.D. Patel, W.D. Snider, Neurotrophic factors and axonal growth, Curr. Opin. Neurobiol. 12 (2002) $523-531$. https://doi.org/10.1016/S0959-4388(02)00372-0.

[26] P. Lu, M.H. Tuszynski, Growth factors and combinatorial therapies for CNS regeneration, Exp. Neurol. 209 (2008) 313-320. https://doi.org/10.1016/j.expneurol.2007.08.004.

[27] M. Lykissas, A. Batistatou, K. Charalabopoulos, A. Beris, The Role of Neurotrophins in Axonal Growth, Guidance, and Regeneration, Curr. Neurovasc. Res. 4 (2007) 143-151. https://doi.org/10.2174/156720207780637216.

[28] B.S. Bregman, M. McAtee, H.N. Dai, P.L. Kuhn, Neurotrophic factors increase axonal growth after spinal cord injury and transplantation in the adult rat, Exp. Neurol. 148 (1997) 475-494. https://doi.org/10.1006/exnr.1997.6705.

[29] M.R. Freeman, Sculpting the nervous system: Glial control of neuronal development, Curr. Opin. Neurobiol. 16 (2006) 119-125. https://doi.org/10.1016/j.conb.2005.12.004.

[30] E. Pompili, V. Ciraci, S. Leone, V. De Franchis, P. Familiari, R. Matassa, G. Familiari, A.M. Tata, L. Fumagalli, C. Fabrizi, Thrombin regulates the ability of Schwann cells to support neuritogenesis and to maintain the integrity of the nodes of Ranvier, Eur. J. Histochem. 64 (2020). https://doi.org/10.4081/ejh.2020.3109.

[31] N. El Seblani, A.S. Welleford, J.E. Quintero, C.G. van Horne, G.A. Gerhardt, Invited review: Utilizing peripheral nerve regenerative elements to repair damage in the CNS, J. Neurosci. Methods. 335 (2020) 108623. https://doi.org/10.1016/j.jneumeth.2020.108623.

[32] K.R. Jessen, P. Arthur-Farraj, Repair Schwann cell update: Adaptive reprogramming, EMT, and stemness in regenerating nerves, Glia. 67 (2019) 421-437. https://doi.org/10.1002/glia.23532.

[33] G. Nocera, C. Jacob, Mechanisms of Schwann cell plasticity involved in peripheral nerve repair after injury, Cell. Mol. Life Sci. (2020) 1-13. https://doi.org/10.1007/s00018-020-03516-9.

[34] K.R. Jessen, R. Mirsky, A.C. Lloyd, Schwann cells: Development and role in nerve repair, Cold Spring Harb. Perspect. Biol. 7 (2015) 1-15. https://doi.org/10.1101/cshperspect.a020487.

[35] J.A. Gomez-Sanchez, K.S. Pilch, M. Van Der Lans, S. V. Fazal, C. Benito, L.J. Wagstaff, R. Mirsky, K.R. Jessen, After nerve injury, lineage tracing shows that myelin and Remak Schwann cells elongate extensively and branch to form repair Schwann cells, which shorten radically on remyelination, J. Neurosci. 37 (2017) 9086-9099. https://doi.org/10.1523/JNEUROSCl.1453-17.2017.

[36] L.X. Wang, X.G. Li, Y.L. Yang, Preparation, properties and applications of polypyrroles, React. Funct. Polym. 47 (2001) 125-139. https://doi.org/10.1016/S1381-5148(00)00079-1.

[37] T.H. Le, Y. Kim, H. Yoon, Electrical and electrochemical properties of conducting polymers, Polymers (Basel). 9 (2017). https://doi.org/10.3390/polym9040150.

[38] M. Mattioli-Belmonte, F. Gabbanelli, M. Marcaccio, F. Giantomassi, R. Tarsi, D. Natali, A. Callegari, F. Paolucci, G. Biagini, Biocharacterisation of tosylate-doped polypyrrole films for biomedical applications, Mater. Sci. Eng. C. 25 (2005) $43-49$. https://doi.org/10.1016/j.msec.2004.04.002.

[39] G. Sabouraud, S. Sadki, N. Brodie, The mechanisms of pyrrole electropolymerization, Chem. Soc. Rev. 29 (2000) $283-293$. https://doi.org/10.1039/a807124a.

[40] C. Li, H. Bai, G. Shi, Conducting polymer nanomaterials: Electrosynthesis and applications, Chem. Soc. Rev. 38 (2009) $2397-2409$. https://doi.org/10.1039/b816681c.

[41] S. Aznar-Cervantes, M.I. Roca, J.G. Martinez, L. Meseguer-Olmo, J.L. Cenis, J.M. Moraleda, T.F. Otero, Fabrication of conductive electrospun silk fibroin scaffolds by coating with polypyrrole for biomedical applications, Bioelectrochemistry. 85 (2012) 36-43. https://doi.org/10.1016/j.bioelechem.2011.11.008.

[42] J.F. Zhou, Y.G. Wang, L. Cheng, Z. Wu, X.D. Sun, J. Peng, Preparation of polypyrrole-embedded electrospun poly(lactic acid) nanofibrous scaffolds for nerve tissue engineering, Neural Regen. Res. 11 (2016) 1644-1652. https://doi.org/10.4103/16735374.193245.

[43] P.M. George, A.W. Lyckman, D.A. Lavan, A. Hegde, Y. Leung, R. Avasare, C. Testa, P.M. Alexander, R. Langer, M. Sur, Fabrication and biocompatibility of polypyrrole implants suitable for neural prosthetics, Biomaterials. 26 (2005) 3511-3519. https://doi.org/10.1016/j.biomaterials.2004.09.037.

[44] A. Esfandiari, PPy covered cellulosic and protein fibres using novel covering methods to improve the electrical property, World Appl. Sci. J. 3 (2008) 470-475. http://www.idosi.org/wasj/wasj3(3)/16.pdf.

[45] D.E. Henton, P. Gruber, J. Lunt, J. Randall, Polylactic Acid Technology: A Review, Nat. Fibers, Biopolym. Biocomposites. 48674 (2005) 527-578. https://doi.org/10.1201/9780203508206.ch16.

[46] J. Lunt, Large-scale production, properties and commercial app, Polym. Degrad. Stab. 3910 (1998) $145-152$. https://doi.org/10.1016/S0141-3910(97)00148-1.

[47] Y. Ramot, M. Haim-Zada, A.J. Domb, A. Nyska, Biocompatibility and safety of PLA and its copolymers, Adv. Drug Deliv. Rev. 107 (2016) 153-162. https://doi.org/10.1016/j.addr.2016.03.012.

[48] D. da Silva, M. Kaduri, M. Poley, O. Adir, N. Krinsky, J. Shainsky-Roitman, A. Schroeder, Biocompatibility, biodegradation and excretion of polylactic acid (PLA) in medical implants and theranostic systems, Chem. Eng. J. 340 (2018) 9-14. https://doi.org/10.1016/j.cej.2018.01.010.

[49] Y. Wan, D. Wen, Preparation and characterization of porous conducting poly(DL-lactide) composite membranes, J. Memb. Sci. 246 
(2005) 193-201. https://doi.org/10.1016/j.memsci.2004.07.032.

[50] G. Shi, M. Rouabhia, Z. Wang, L.H. Dao, Z. Zhang, A novel electrically conductive and biodegradable composite made of polypyrrole nanoparticles and polylactide, Biomaterials. 25 (2004) 2477-2488. https://doi.org/10.1016/j.biomaterials.2003.09.032.

[51] Z. Wang, C. Roberge, L.H. Dao, Y. Wan, G. Shi, M. Rouabhia, R. Guidoin, Z. Zhang, In vivo evaluation of a novel electrically conductive polypyrrole/poly(D,L- lactide) composite and polypyrrole-coated poly(D,L-lactide-co-glycolide) membranes, J. Biomed. Mater. Res. - Part A. 70 (2004) 28-38. https://doi.org/10.1002/jbm.a.30047.

[52] M.A. Woodruff, D.W. Hutmacher, The return of a forgotten polymer - Polycaprolactone in the 21st century, Prog. Polym. Sci. 35 (2010) 1217-1256. https://doi.org/10.1016/j.progpolymsci.2010.04.002.

[53] C.X.F. Lam, D.W. Hutmacher, J.T. Schantz, M.A. Woodruff, S.H. Teoh, Evaluation of polycaprolactone scaffold degradation for 6 months in vitro and in vivo., J. Biomed. Mater. Res. A. 90 (2009) 906-919. https://doi.org/10.1002/jbm.a.32052.

[54] J. Schindelin, I. Arganda-Carreras, E. Frise, V. Kaynig, M. Longair, T. Pietzsch, S. Preibisch, C. Rueden, S. Saalfeld, B. Schmid, J.-Y. Tinevez, D.J. White, V. Hartenstein, K. Eliceiri, P. Tomancak, A. Cardona, Fiji: an open-source platform for biological-image analysis, Nat. Methods. 9 (2012) 676-682. https://doi.org/10.1038/nmeth.2019.

[55] S.J.P. Callens, R.J.C. Uyttendaele, L.E. Fratila-Apachitei, A.A. Zadpoor, Substrate curvature as a cue to guide spatiotemporal cell and tissue organization, Biomaterials. 232 (2020) 119739. https://doi.org/10.1016/j.biomaterials.2019.119739.

[56] C.G. Rolli, H. Nakayama, K. Yamaguchi, J.P. Spatz, R. Kemkemer, J. Nakanishi, Switchable adhesive substrates: Revealing geometry dependence in collective cell behavior, Biomaterials. 33 (2012) 2409-2418. https://doi.org/10.1016/j.biomaterials.2011.12.012.

[57] K. Doxzen, S.R.K. Vedula, M.C. Leong, H. Hirata, N.S. Gov, A.J. Kabla, B. Ladoux, C.T. Lim, Guidance of collective cell migration by substrate geometry, Integr. Biol. 5 (2013) 1026. https://doi.org/10.1039/c3ib40054a.

[58] Y. tae Kim, V.K. Haftel, S. Kumar, R. V. Bellamkonda, The role of aligned polymer fiber-based constructs in the bridging of long peripheral nerve gaps, Biomaterials. 29 (2008) 3117-3127. https://doi.org/10.1016/j.biomaterials.2008.03.042.

[59] E. Schnell, K. Klinkhammer, S. Balzer, G. Brook, D. Klee, P. Dalton, J. Mey, Guidance of glial cell migration and axonal growth on electrospun nanofibers of poly- $\varepsilon$-caprolactone and a collagen/poly- $\varepsilon$-caprolactone blend, Biomaterials. 28 (2007) 3012-3025. https://doi.org/10.1016/j.biomaterials.2007.03.009. 

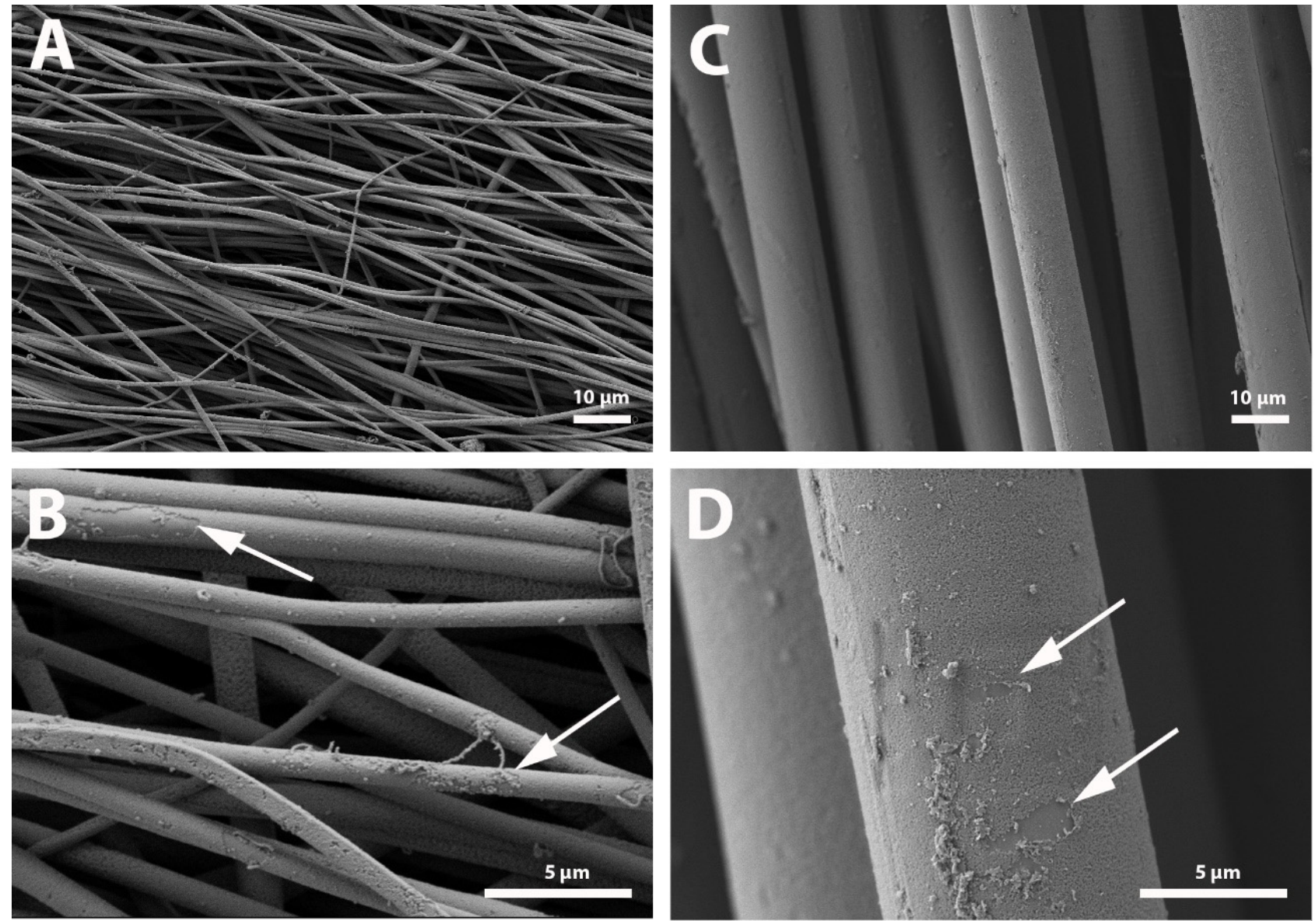

Fig. S1. FESEM images of PLA-PPy NF ( $A$ and $B$ ) and MF ( $C$ and $D)$ substrates after the PPy coating using the coating protocol $C 1$. The arrows in $B$ and $D$ indicate areas where the PPy coating fails to completely coat the fibres, leading to an inhomogeneous coating. Scale bar $=10 \mu \mathrm{m}(\mathrm{A}$ and $C)$ and $5 \mu \mathrm{m}(B$ and D). 